\title{
A Tracer Study on (2011 - 2013) Debre Berhan University Graduates Integration in to the World of Work
}

\author{
Getachew Tefera \\ College of Pedagogy, Department of Education, Debre Berhan University, Debre Berhan, Ethiopia \\ Email address: \\ getsion2005@gmail.com \\ To cite this article: \\ Getachew Tefera. A Tracer Study on (2011 - 2013) Debre Berhan University Graduates Integration in to the World of Work. International \\ Journal of Secondary Education. Vol. 6, No. 2, 2018, pp. 37-45. doi: 10.11648/j.ijsedu.20180602.13
}

Received: August 22, 2018; Accepted: September 11, 2018; Published: October 11, 2018

\begin{abstract}
Higher Educational Institutions are responsible for ensuring the quality of education they offer to their learners. The graduate tracer study is the one among the methods these institutions can make use of in order to monitor the quality of their programs. Debre Berhan University recognized graduate tracer study as a means of ensuring the quality of education and has incorporated the need for conducting a comprehensive graduate tracer study in its annual plan for the 2013/2014 academic calendar. The major objective of this study was to obtain reliable and valid information that would help to improve the quality of Debre Berhan University's academic programs. A cross-sectional study design was conducted February 2014, from three regional (Amhara, SNNPR and Oromya) and Addis Ababa city administration. The target populations of the survey were degree graduates of Debre Berhan University $(2011$ - 2013) and their employers. Sample of graduates were taken using the snowball sampling technique and the purposive sampling technique was employed to select employers. Regarding to the type of organizations where graduates' were first employed, $79.9 \%$ reported government placements and only $11.2 \%$ employed by private organizations. The majority of graduates (65.9\%) believed that their educational level/qualification fit the kind of job they were assigned to. However, $31.5 \%$ of them complained that their employment did not have any relation to their educational qualifications. Over $76 \%$ of the graduates considered the contents of the major field of their study and variety of the contents of the courses to be favorable. With regard to the level of satisfaction of employers With DBU graduates professional situation was $64.4 \%$, similarly $69.1 \%$ of the graduates themselves satisfied with their professional competence. Bachelor degrees for graduates were evaluated as useful for job placement and a key for performing their job properly as much as the employers expected from graduates. The University needs to encourage its students to be familiar with basic computer and related technology skills, by providing them with basic facilities and creating conducive environments in which students are motivated to use ICT regularly throughout their learning years.
\end{abstract}

Keywords: Tracer Study, Descriptive, MOE

\section{Introduction}

Higher education is a key institution for transforming a country to the aspired level of development. It serves this purpose through enhancing the personal development of individuals as well as public benefits. Regarding personal development, higher education facilitates social mobility, sound treatment and respect, creating new job opportunities and healthier and wealthier citizens. In terms of public benefits, higher education results in increased production, innovative, entrepreneurial, economics, and political stability. With this understanding, the Ethiopian government has been embarking on expanding higher education on a mass scale.
For instance, the number of public higher institution, which was two in 1991, has now become more than 31 Universities. The number of programs at undergraduate and postgraduate level, including the number of students at each level, is rapidly rising.

It is obvious that as the number of institutions and students increases, maintaining quality and relevance of education is questionable unless a sufficient system of monitoring and ensuring quality and relevance of education is in place. With this awareness, the Higher Education Relevance and Quality Agency has been established with proclamation number 351/2003 (Federal Democratic Republic of Ethiopia, [1]. With this proclamation, HERQA has been given the directive 
of ensuring the quality and relevance of higher education provided in the country, with both private and public higher learning institutions. To this end, each higher learning institution in the country is required to provide evidence of an internal quality assurance system through which the quality and relevance of training, research and services is ensured. In order to discharge this responsibility, HERQA developed guidelines for commencing self-evaluation and an external audit, which serves to validate the self-evaluation report, provided that the self-evaluation document is inclusive and up to the expectations set [2-4].

Debre Berhan University as higher institution developed academic quality assurance and relevance directorate in 2010 GC. The directorate has worked to provide quality education for the University students. However, these quality assessments did not provide a full picture of the quality of education and training offered by the University, as all these studies focus on the input and process aspect of education, regardless of its output. That is why the University has developed additional department, which is an alumni officer to assess external effectiveness of the university and developed short comes and strength of the University.

In general, conducting a graduate tracer study helps to provide valuable information about the effectiveness of graduates, strengths and shortcomings of educational programs. In this way, a graduate tracer study provides vital information for higher learning institutions to obtain relevant information that may be used for minimizing any possible deficits in a given educational program in terms of content, delivery and relevance and for further development of the institution in the context of quality assurance (Schomburg, 2003). With this background, Debre Berhan University (DBU) has incorporated the need for conducting a comprehensive graduate tracer study in its annual plan for the $2013 / 2014$ academic calendar. This tracer study was meant to get reliable and valid information that can aid the improvement of DBU Programs. Those are to assess degree resource and credential for job placement, evaluate the relevance of study programs offered by the university in the world of work, equipped with competencies (Knowledge, skills, abilities and personal attributes) of the graduates, level of graduate satisfaction in the programs and the level of employer satisfaction in DBU graduates.

\section{Material and Methods}

\subsection{Study Design}

A cross sectional descriptive study design was employed in order to investigate the effectiveness of DBU graduates.

\subsection{The Study Area and Period}

The survey was carried out in three major regional state (Oromya, SNNP and Amhara) and their surrounding zonal and woreda towns and Addis Ababa city administration. Data collection was conducted February 2014 and the data was included all department graduates. The target population of the survey was degree graduates of DBU (2011 - 2013) and their employers.

\subsection{Sample Size}

The total number of graduates in three years 5456 with $5 \%$ margin of error, a design effect of 2 and return rate of $80 \%$ for the total data. The minimum sample size required for the survey was 945 . This was calculated as:

$$
n_{o}=N / 1+N(e)^{2}=5456 / 1+5456(0.05)^{2}=945[5]
$$

Where $\mathrm{N}=$ number of graduates, $\mathrm{e}=$ margin of error and $\mathrm{n}_{\mathrm{O}}=$ initial sample size

Since we use clusters of areas to locate graduates, we may need to consider the design effect in determination of sample size required was calculated to be 2 times the initial sample size is 745 . In addition, considering the return rate of $80 \%$, the final minimum sample size will be 931(745/0.8).

\subsection{Sampling Technique}

The snowball sampling technique was used to locate and select graduates. A purposive sampling technique was used to select employers. However, through snow ball technique used for graduate there was the possibility of going outside the short listed potential employers. These employers were then included in the list of potential employer for possible utilization in the future.

\subsection{Instruments}

Pre-tested structured questionnaires were used to collect data needed to answer the survey questions during phone communication. The instruments was adopted on the basis of thematic areas identified from survey questionnaires prepared by ETQAA 2010 for employers' satisfaction, handbook for graduate tracer study [6] and urban environmental management graduate tracer study [7]. In this way, for the two sources (graduates and employers), similar items that address background information, graduates' current knowledge, skills and personal attributes, satisfaction level in DBU graduates, and perceived strengths and areas of improvement, was developed.

\subsection{Data Collection Procedure}

After collecting all sample graduates data from the study area and the target group we use selected persons were served as a contact person. In consultation with these that was selected.

\subsection{Data Processing and Analysis}

The collected data/questionnaires was edited, and coded. The data was finally export to SPSS version 20 for analysis. Descriptive statistical data analysis techniques were explored to analyze the data (tables, graphs/ charts and percentage) were used to present the results of the analysis. 


\subsection{Ethical Considerations}

The research was undertaken after clearance has been obtained from the University. Consent to participate in the study was obtained from each participant before the data collectors undertook data collection.

\section{Results}

Data was collected from 931 graduates and 399 employers of graduates. The following are the results compiled from different categories of the effectiveness of Debre Berhan University's program on graduates' performance at work.

Table 1. Graduates' Demographic Characteristics and College, 2014.

\begin{tabular}{llll}
\hline Characteristics & & Mean & Standard deviation \\
\hline Age & & $\mathbf{2 5 . 5 1}$ & $\mathbf{5 . 6 4}$ \\
\hline Category response & & Frequency (n) & Percentage (\%) \\
\hline \multirow{2}{*}{ Sex } & Female & 347 & 37.3 \\
& Male & 584 & 62.7 \\
& CNCS & 201 & 21.6 \\
& CBE & 338 & 36.3 \\
College & CCS & 94 & 10.1 \\
& CSSH & 150 & 16.1 \\
& CANRS & 80 & 8.6 \\
\hline
\end{tabular}

As indicated in table 1, the average age of graduates is 25.51 ( \pm 5.64) with a minimum and maximum of 20 to 46 years, respectively. Sex wise, more of them were males 584 (62.7\%) the rest $347(37.3 \%)$ were females. The majority of the respondents were from the College of Business and Economics (CBE) (36.3\%) and College of Natural and Computational
Science (CNCS) (21.6\%), College of Social Science and Humanities (CSSH) (16.1\%), whereas other Colleges such as, the College of Computing Science (CCS) (10.1\%), College of Agriculture and Natural Resource Management (CANRM) $(8.6 \%)$ and College of Medicine and Health Science (CMHS) $(7.3 \%)$ were more evenly represented.

Table 2. Graduates' Reflection on the Effectiveness of Provision of Academic Programs, 2014.

\begin{tabular}{|c|c|c|c|c|c|c|c|c|c|c|}
\hline \multirow{2}{*}{ Characteristics (Variable) } & \multicolumn{2}{|c|}{ Very poor } & \multicolumn{2}{|c|}{ Poor } & \multicolumn{2}{|l|}{ Fair } & \multicolumn{2}{|c|}{ Good } & \multicolumn{2}{|c|}{ Excellent } \\
\hline & №. & $\%$ & No. & $\%$ & No. & $\%$ & No. & $\%$ & №. & $\%$ \\
\hline Course contents of major field of study & 26 & 2.8 & 60 & 6.6 & 129 & 14.1 & 416 & 45.5 & 283 & 31.0 \\
\hline Varieties of courses of fired & 12 & 1.3 & 42 & 4.5 & 154 & 16.5 & 499 & 53.6 & 224 & 24.1 \\
\hline
\end{tabular}

Table 2: shows that over $76 \%$ of the graduates considered the contents of the major field of their study and variety of the contents of the courses to be favorable. However, the fact that a small portion of graduates who opted for fair and unfavorable in both cases needs attention. The design of the degree programs was also posed to graduates as a means of evaluating the effectiveness of academic programs provided. In this regard, $75.2 \%$ of respondents gave positive feedback while $14.8 \%$ and $10.0 \%$ considered design as fair and unsatisfactory, respectively.

As understood from table 3 below, most of graduates $61.9 \%$ found academic advice provided to them as good or excellent while $22.4 \%$ of them regarded it as fair. More over $65.9 \%$ of graduates acknowledge the cooperative learning opportunity they had had. Analysis of graduates related to the teaching and learning process shows that more than half of them rated the practical emphasis of teaching $52.7 \%$, teachers' content and pedagogical competencies $62.1 \%$, and provision of the real world of work $51.7 \%$ as excellent/good. However, a relatively small percentage of them considered the chance to participate in staff research $44.3 \%$ as encouraging when respondents of those who rated good/excellent are considered.

Table 3. Graduates' Reflection on the Teaching and Learning Processes, 2014.

\begin{tabular}{|c|c|c|c|c|c|c|c|c|c|c|}
\hline \multirow{2}{*}{ Characteristics (Variable) } & \multicolumn{2}{|c|}{ Very poor } & \multicolumn{2}{|c|}{ Poor } & \multicolumn{2}{|l|}{ Fair } & \multicolumn{2}{|c|}{ Good } & \multicolumn{2}{|c|}{ Excellent } \\
\hline & No. & $\%$ & No. & $\%$ & No. & $\%$ & No. & $\%$ & No. & $\%$ \\
\hline Academic advices offered in general & 42 & 4.5 & 103 & 11.1 & 209 & 22.4 & 422 & 45.3 & 155 & 16.6 \\
\hline Practical emphasis of teaching and learning & 0 & 0 & 232 & 24.9 & 194 & 20.8 & 314 & 33.7 & 85 & 9.1 \\
\hline Teachers quality knowledge and pedagogical skills & 36 & 3.9 & 119 & 12.8 & 197 & 21.8 & 438 & 47.0 & 141 & 15.1 \\
\hline Participate in staff research projects & 0 & 0 & 266 & 28.6 & 170 & 18.3 & 342 & 36.7 & 71 & 7.6 \\
\hline Research emphasis of teaching and learning & 33 & 3.5 & 175 & 18.8 & 232 & 24.9 & 406 & 43.6 & 85 & 9.1 \\
\hline Contac students fellow / collaborative learning & 17 & 1.8 & 101 & 10.8 & 199 & 21.4 & 447 & 48.0 & 167 & 17.9 \\
\hline
\end{tabular}

As shown in the figure 1, regarding the overall assessment condition, $66 \%$ of graduates found the overall assessment practices as positive while $16.2 \%$ fair and $17.8 \%$ of them regarded it as unfavorable. Similarly, the majority of graduates $68 \%$ were optimistic about the existing orientation on examination process. 


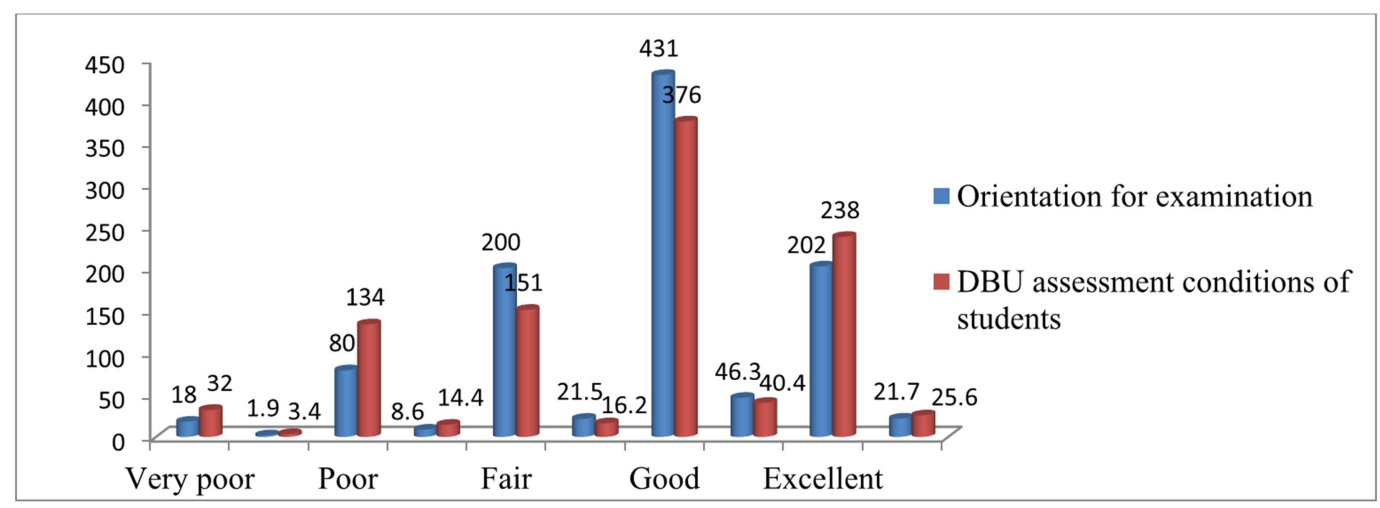

Figure 1. Students Performance Assessment, 2014.

Figure 2, shows that, more than half of graduates' respondents were satisfied with library services $54.5 \%$ the strength includes female students support and in contrast supply of learning materials was less $38.6 \%$.

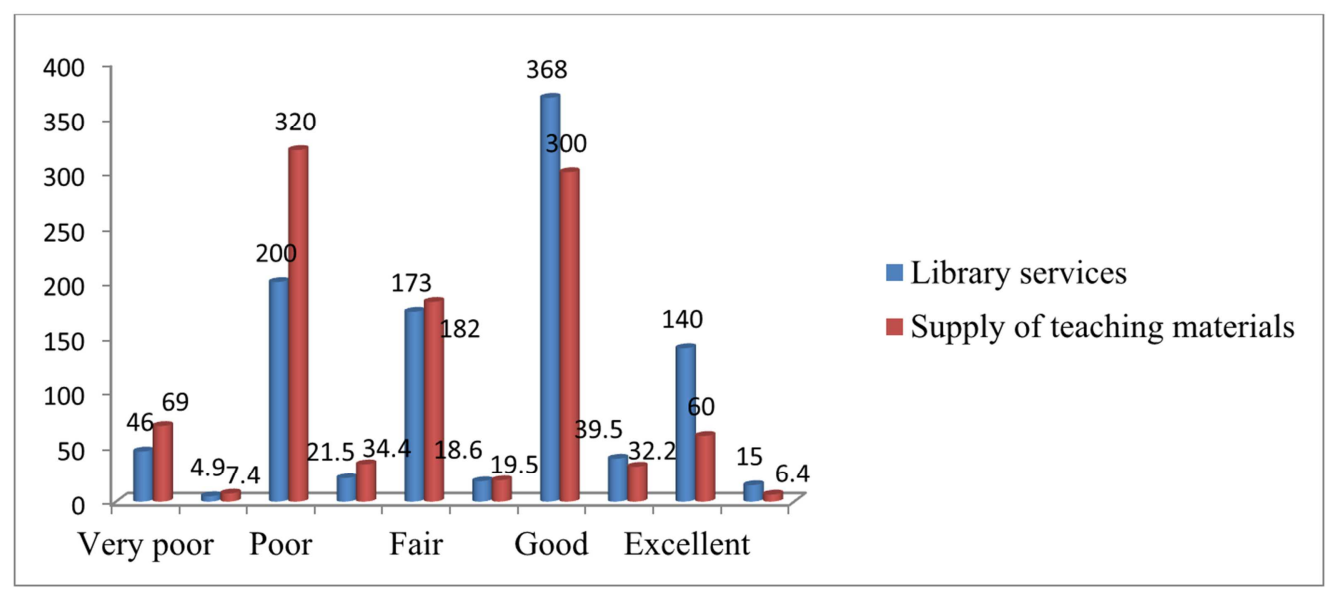

Figure 2. Students Support Services, 2014.

To assess the degree of compatibility of graduates to the knowledge required in the real world of work, three interrelated questions addressing in-depth knowledge of their field of study, conceptual understanding of the task they were assigned to and the capacity for understanding things from diverse perspectives were presented to them.

The information in the below table 4 reflects that most of the graduates; $663(71.2 \%)$ reported that they had successfully mastered the required knowledge in their field of studied. Similarly $629(67.6 \%)$ of respondents claimed that they effectively performed at the level of conceptual understanding required by the task they were assigned to. In addition to these they responded that they were capable of perfectly demonstrating reflecting thinking (67.8\%) demanded of them in the work place. Graduates of different colleges were compared with respect to self-perception of the level of field-related and transferable knowledge. While an appreciable size of them ranked their level of knowledge as adequate/excellent.

Table 4. Graduates compliance to the knowledge required by the world of work, 2014.

\begin{tabular}{|c|c|c|c|c|c|c|c|c|c|c|}
\hline \multirow{2}{*}{ Characteristics (Variable) } & \multicolumn{2}{|c|}{ Not at all } & \multicolumn{2}{|c|}{ Very little } & \multicolumn{2}{|c|}{ Fairly } & \multicolumn{2}{|c|}{ Adequate } & \multicolumn{2}{|c|}{ Very well } \\
\hline & No. & $\%$ & №. & $\%$ & No. & $\%$ & No. & $\%$ & No. & $\%$ \\
\hline In- depth knowledge of the field of study & 18 & 1.9 & 73 & 7.8 & 176 & 18.9 & 409 & 43.9 & 254 & 27.3 \\
\hline $\begin{array}{l}\text { Demonstrating conceptual knowledge related to the type of job } \\
\text { or tasks assigned }\end{array}$ & 39 & 4.2 & 57 & 6.1 & 205 & 22.0 & 351 & 37.7 & 278 & 29.9 \\
\hline Demonstrating and understanding by concepts of diverse way & 11 & 1.2 & 68 & 7.3 & 219 & 23.6 & 371 & 40.0 & 258 & 27.8 \\
\hline
\end{tabular}

Regarding skills, graduates were asked to evaluate their competency in the skill areas required by the world of work such as task-specific, computing and computer, communication, research and planning and leadership and entrepreneurial skills. The results are presented in the following tables. As shown from Table 5, on average above $60 \%$ of graduates reported that they were fulfilling the job specific skills required from them. This was true with evaluating their communication, writing, reading skill as well as computing and basic computer skills. 
Table 5. Job related, communication, computing and computer skills of graduates, 2014.

\begin{tabular}{|c|c|c|c|c|c|c|c|c|c|c|}
\hline \multirow{2}{*}{ Characteristics (Variable) } & \multicolumn{2}{|c|}{ Not at all } & \multicolumn{2}{|c|}{ Very little } & \multicolumn{2}{|c|}{ Fairly } & \multicolumn{2}{|c|}{ Adequate } & \multicolumn{2}{|c|}{ Very well } \\
\hline & No. & $\%$ & No. & $\%$ & No. & $\%$ & No. & $\%$ & No. & $\%$ \\
\hline $\begin{array}{l}\text { Using specific technical skills related to the type of job or } \\
\text { tasks you perform }\end{array}$ & 21 & 2.3 & 83 & 8.9 & 269 & 28.9 & 320 & 34.4 & 237 & 25.5 \\
\hline Communicated well orally on job-related manners & 24 & 2.6 & 68 & 7.3 & 172 & 18.5 & 406 & 43.6 & 260 & 27.9 \\
\hline Writing effectively in a clear and correct manner & 15 & 1.6 & 43 & 4.6 & 157 & 16.9 & 377 & 40.5 & 338 & 36.3 \\
\hline Reading or speaking a foreign language & 11 & 1.2 & 115 & 12.4 & 231 & 24.8 & 374 & 40.2 & 200 & 21.5 \\
\hline Computing skills & 5 & 0.5 & 88 & 9.5 & 284 & 30.5 & 314 & 33.7 & 240 & 25.8 \\
\hline
\end{tabular}

Graduates evaluated themselves against 4 items related to research and planning skills. As shown from Table 6, on average more than $65 \%$ of the respondents stated that they satisfied the research and planning skills required by their job. More than $66 \%$ of graduates also evaluated their leadership and entrepreneurial skills.

Table 6. Research and Planning Skills of Graduates 2014.

\begin{tabular}{|c|c|c|c|c|c|c|c|c|c|c|}
\hline \multirow{2}{*}{ Characteristics (Variable) } & \multicolumn{2}{|c|}{ Not at all } & \multicolumn{2}{|c|}{ Very little } & \multicolumn{2}{|c|}{ Fairly } & \multicolumn{2}{|c|}{ Adequate } & \multicolumn{2}{|c|}{ Very well } \\
\hline & №. & $\%$ & No. & $\%$ & No. & $\%$ & №. & $\%$ & No. & $\%$ \\
\hline $\begin{array}{l}\text { Assessing validity arguments based on qualitative and quantitative } \\
\text { information }\end{array}$ & 6 & 0.6 & 97 & 10.4 & 224 & 24.1 & 401 & 43.1 & 203 & 21.8 \\
\hline Research skills & 45 & 4.8 & 103 & 11.1 & 279 & 30.0 & 367 & 39.4 & 137 & 14.7 \\
\hline Planning and organizational skills to determine tasks and resource & 36 & 3.9 & 84 & 0.9 & 185 & 19.9 & 439 & 47.2 & 187 & 20.1 \\
\hline Setting priorities and allocating time efficiently & 6 & 0.6 & 93 & 10.0 & 171 & 18.4 & 377 & 40.5 & 284 & 30.5 \\
\hline
\end{tabular}

To request about the degree of respect and appreciation the graduates have for Debre Berhan University, they were asked to rate the degree to which they were satisfied with their profession as a whole.

Table 7. Graduates Level of Satisfaction, 2014.

\begin{tabular}{|c|c|c|c|c|c|c|c|c|c|c|}
\hline \multirow[t]{2}{*}{ Characteristics (Variable) } & \multicolumn{2}{|c|}{ Very dissatisfied } & \multicolumn{2}{|c|}{$\begin{array}{l}\text { Generally } \\
\text { dissatisfied }\end{array}$} & \multicolumn{2}{|c|}{ Undecided } & \multicolumn{2}{|c|}{$\begin{array}{l}\text { Generally } \\
\text { satisfied }\end{array}$} & \multicolumn{2}{|c|}{ Very satisfied } \\
\hline & No. & $\%$ & No. & $\%$ & №. & $\%$ & №. & $\%$ & No. & $\%$ \\
\hline Satisfied with your professional competence & 57 & 6.1 & 111 & 11.9 & 120 & 12.9 & 439 & 47.9 & 204 & 21.9 \\
\hline $\begin{array}{l}\text { Demonstrating leadership ability of motivating a } \\
\text { group of people towards common goal }\end{array}$ & 0 & 0 & 64 & 6.9 & 147 & 15.8 & 316 & 33.9 & 403 & 43.3 \\
\hline $\begin{array}{l}\text { Knowledge, skills, aptitude and motivation to start, } \\
\text { develop and run original business }\end{array}$ & 0 & 0 & 74 & 7.9 & 184 & 19.8 & 365 & 39.2 & 305 & 32.8 \\
\hline
\end{tabular}

Most of graduates $643(69.1 \%)$ rated that they were satisfied with their current professional competencies while 120 (12.9\%) of them took the middle ground. $168(18 \%)$ of graduates reported that they were dissatisfied with their current professional competencies. In a similar way, graduates ranked DBU favorable compared to other public universities in the country. More than $90 \%$ graduates ranked DBU as first to fifth show in the graph below figure 3 .

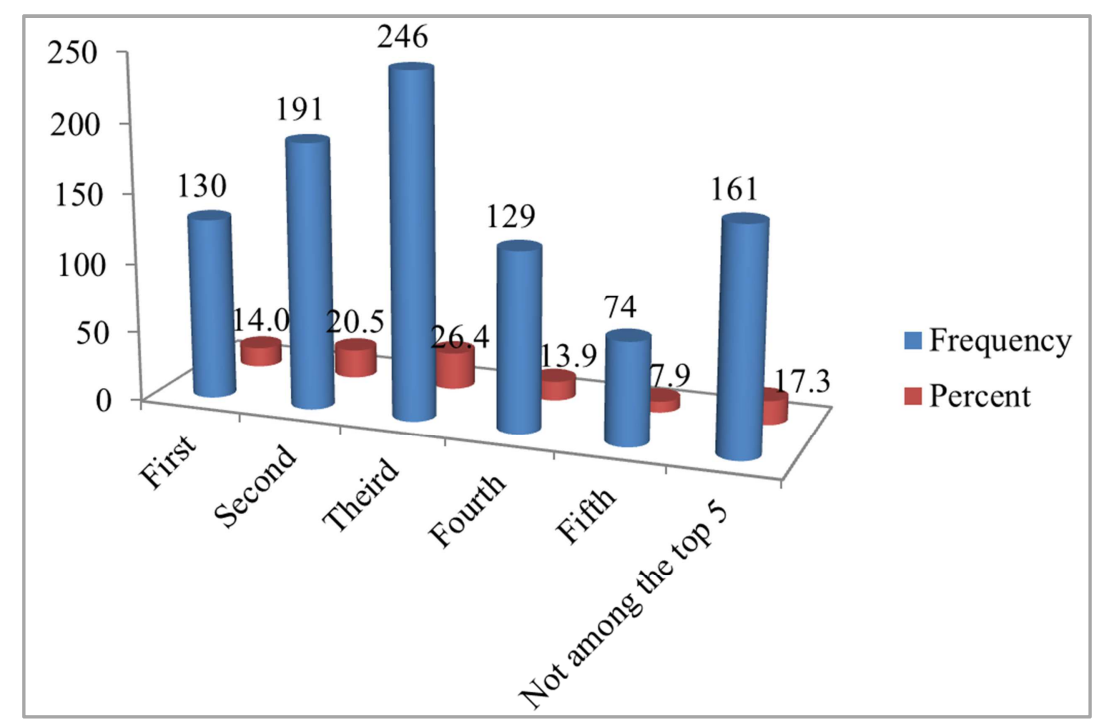

Figure 3. Rank of students of $D B U$. 
Educational qualification of graduates and level of satisfaction of employers with graduates' professional situation.

With regard to the graduates' educational qualification for the job, 55.9\% of employers admitted that their expectation had been exceeded, while $43.1 \%$ of them characterized graduates' education qualification as adequate. Similarly, $64.4 \%$ of employers rated their level of satisfaction with graduates' professional competencies generally as satisfactory where as $10.5 \%$ of them had an ambivalent option.

Table 8. Education qualification level of satisfaction of employers', 2014.

\begin{tabular}{|c|c|c|c|}
\hline & & No. & $\%$ \\
\hline \multirow{5}{*}{ Educational qualification of the graduates } & Extremely good & 90 & 22.6 \\
\hline & More than adequate & 133 & 33.3 \\
\hline & Sufficient & 172 & 43.1 \\
\hline & Less than sufficient & 4 & 1.0 \\
\hline & Total & 339 & 100 \\
\hline \multirow{5}{*}{$\begin{array}{l}\text { Level of satisfaction of employers With DBU } \\
\text { graduates professional situation }\end{array}$} & Very satisfied & 109 & 27.3 \\
\hline & Generally satisfied & 148 & 37.1 \\
\hline & Generally dissatisfied & 83 & 20.8 \\
\hline & Very dissatisfied & 17 & 4.3 \\
\hline & Total & 399 & 100 \\
\hline
\end{tabular}

Knowledge

Employers assessed the level of field-related and transferable knowledge of graduates as shown in table 8 . More than $60 \%$ employers describe field-related knowledge of graduates as high or very high; on the other hand, more than $50 \%$ of them rated the level of transferable knowledge of graduates as high or very high.

Table 9. Employers' reflection on the compliance of graduates to the knowledge required by the World of work, 2014.

\begin{tabular}{|c|c|c|c|c|c|c|c|}
\hline & & Very low & Low & Fair & High & Very high & Total \\
\hline \multirow{2}{*}{ Depth knowledge of her/his field of study } & No & 2 & 4 & 150 & 150 & 44 & 399 \\
\hline & $\%$ & 0.5 & 1.0 & 37.8 & 37.8 & 11.0 & 100 \\
\hline \multirow{2}{*}{ Demonstrating conceptual knowledge related to the type of job } & No & 11 & 26 & 179 & 145 & 38 & 399 \\
\hline & $\%$ & 2.8 & 6.5 & 44.9 & 26.3 & 9.5 & 100 \\
\hline Demonstrating effective understanding by restarting & No & 11 & 7 & 174 & 177 & 30 & 399 \\
\hline information, ideas, \& concepts indivers ways & $\%$ & 2.8 & 1.8 & 43.6 & 44.4 & 7.5 & 100 \\
\hline
\end{tabular}

Communication, Computing, Computer, and Job-related skills

Communication, job-related, computer, personal and research and planning skills were the categories for evaluating the skills of graduates by their employers. Communicating well orally on job-related matters and writing effectively in a clear and correct manner were described as "above average" by $61 \%$ and $42 \%$ of employers, respectively. Job - employers described related skills of graduates as $48 \%$ above average. In general, employers also observed a gap in academic achievement measured by CGPA and practical application of knowledge in real-life work. "Graduates grade is so high where as their performance in real work is unexpectedly poor." Likewise, the rating for basic computer skills suggests that $50 \%$ of employers were not satisfied with the abovementioned skills of graduates.

Table 10. Employers Perception of DBU Graduate Competence and Job-Related Skills, 2014.

\begin{tabular}{|c|c|c|c|c|c|c|c|}
\hline & & Very low & Low & Fair & High & Very high & Total \\
\hline \multirow{2}{*}{ Using specific technical skill related to the type of job } & No. & 11 & 34 & 163 & 173 & 18 & 399 \\
\hline & $\%$ & 2.8 & 8.5 & 40.9 & 43.4 & 4.5 & 100 \\
\hline \multirow{2}{*}{ Communicating well orally on job-related matters } & No. & 18 & 3 & 135 & 175 & 68 & 399 \\
\hline & $\%$ & 4.5 & 0.8 & 33.9 & 43.9 & 17.0 & 100 \\
\hline \multirow{2}{*}{ Writing effectively in a clear and correct manner } & No. & 37 & - & 154 & 163 & 45 & 399 \\
\hline & $\%$ & 9.3 & - & 38.6 & 40.9 & 11.3 & 100 \\
\hline Reading and peaking a foreign Language & No. & 22 & 88 & 158 & 109 & 22 & 399 \\
\hline \multirow{2}{*}{ Having basic computer skills } & No. & 17 & 61 & 154 & 126 & 41 & 399 \\
\hline & $\%$ & 4.3 & 15.3 & 38.6 & 31.6 & 10.3 & 100 \\
\hline
\end{tabular}

Personal attributes

Graduates personal attributes were also appraised by employers another skill measurement area. Nine different items were used to judge personal attributes the items were: evaluating one's own thinking, performing tasks accurately, being productive in completion of work, creating innovative strategies to meet identified needs, adapting to new situations, taking responsibility, being open and accepting of constructive criticism, personal presentation and understanding social problems. In generally terms, 
performing tasks accurately, personal presentation, being productive in completion of work, being open and accepting of constructive criticism, understanding social problems and personal presentation were on average rated as more than satisfactory by more than $60 \%$ of employers. The level of graduates, creativity, adaptive to new situations and evaluating one's own thinking for problem solving were ranked as fair or less by over $40 \%$ of employers. In opposite to the above findings, communication with employers data indicates that lack of discipline constitute great problem on graduates.

Table 11. Assessment of Personal Attributes Of Graduates by Employers, 2014.

\begin{tabular}{|c|c|c|c|c|c|c|c|}
\hline & & Very low & Low & Fair & High & Very high & Total \\
\hline \multirow{2}{*}{ Depth knowledge of her/his field of study } & No & 12 & 33 & 175 & 152 & 27 & 399 \\
\hline & $\%$ & 3.0 & 8.3 & 43.9 & 38.1 & 6.8 & 100 \\
\hline \multirow{2}{*}{ Demonstrating conceptual knowledge related to the type of job } & No & - & 19 & 127 & 202 & 51 & 399 \\
\hline & $\%$ & - & 4.8 & 31.8 & 50.6 & 12.8 & 100 \\
\hline \multirow{5}{*}{$\begin{array}{l}\text { Demonstrating effective understanding by restarting } \\
\text { information, ideas, \& concepts indivers ways }\end{array}$} & No & 21 & 21 & 142 & 186 & 50 & 399 \\
\hline & $\%$ & 5.3 & 5.3 & 35.6 & 46.6 & 12.5 & 100 \\
\hline & No & - & 28 & 135 & 164 & 72 & 399 \\
\hline & No & 10 & 95 & 169 & 93 & 32 & 399 \\
\hline & $\%$ & 2.5 & 23.8 & 42.4 & 23.3 & 8.8 & 100 \\
\hline
\end{tabular}

Finally, employers were asked to rank the university in terms of producing qualified graduates among higher learning universities in the country. $7.5 \%$ of employers ranked DBU first, $24.3 \%$ second, $35.6 \%$ third, while $7.3 \%$ of the employers did not believed that DBU stands among the top 5 .

Table 12. Employers ranking DBU against other public universities, 2014.

\begin{tabular}{lllllll}
\hline Rank & First & Second & Third & Fourth & Fifth & Not among the top 5 \\
\hline No. & 30 & 97 & 142 & 68 & 33 & 29 \\
$\%$ & 7.5 & 24.3 & 35.6 & 17.0 & 8.3 & 7.3 \\
\hline
\end{tabular}

\section{Discussion}

Conserving to the usefulness of DBU degree as asset a viable credential for job placement

Findings from employers and graduates showed positive support for the programs as a whole. In terms of job search duration, more than $85 \%$ of graduates report that they secure a job within six months of their graduation. Among these, $32.9 \%$ secure a job up on graduation including those who reported to have a job before graduation $(4.4 \%)$ as well as those who were placed by the government right up on graduation $(28.5 \%)$, where as $52.3 \%$ of graduates secured jobs within six months. These ratios are near to the target set in the strategic plan of the university that aims to ensure the employability of $90 \%$ of graduates within six months [8] However, there is a message for the university; it needs to work hard in order to fill the gap of the $14.9 \%$ remaining unemployed within the specified six months.

Around $80 \%$ of DBU graduates received employment from government agencies, which may show that DBU programs are in line with national development agenda. Moreover, $66 \%$ of graduates said that their educational level was an excellent fit with the type of job they have found. CMHS graduates were rated high in the fit with the type of job they have found and their educational level while the CSSH graduates came last related to other colleges in DBU. Thus, high employability of graduates and their relative effectiveness of job could be indicating the usefulness of DBU degree for employment.

Relevance of study program

In the course contents of the major field of study (76.5\%), varieties of courses offered $(77.7 \%)$, the design of degree program $(75.2 \%)$, the corresponding proportion of graduates reported that their satisfaction level was more than the average. Hence, these findings show for the quality of curricula the university has been offering. However, it is worthwhile to consider areas to consider areas participates stressed for possible improvement while answering openended quaternaries maintaining the balance of theory and practical emphasis research methodology and information communication technology applications in education ( including access of computer, internet and reference books etc). As with academic programs, graduates were given opportunities to reflect on the qualit y of general teaching and learning possesses they had experienced while at DBU. In this case, the average of responses to the majority of identified indicators of teaching and learning processes (academic advice offered, teaching quality in terms of knowledge, research emphasis in teaching and learning, provision for real world of work and opportunities for collaborating learning) as positive. On opposite to this, emphasis of teaching and participation in staff research was reported to be below average.

Student assessment is one of defining elements of teaching and learning processes [9]. In this case these regard the respondents' analysis of graduates' shows that they were happy with the general assessment conditions and orientation about the purpose of examination. This shows the achievement

Knowledge, skills and personal attribute of DBU graduates

One among the major objectives of education policy in Ethiopia is "developing the mental and problem solving capacity of individuals by endowing students with the necessary knowledge" [10]. Regarding DBU graduates' indepth knowledge of their field of study, their demonstrating of conceptual knowledge related to the type of job they 
perform, and their demonstration of effective understanding in the diverse way, the 3 qualitative and quantitative data showed that graduates and employers evaluated them positively. As an example, about $70 \%$ of graduates evaluated themselves as high in the three mentioned types of knowledge. Over 60\% DBU graduates', employers rated graduates as higher or above average. However, it is advisable to consider the comment provided by the employers regarding the difference between the graduates CGPA and with their current performance. This could be because teaching and learning process at DBU focuses more on theoretical knowledge than practical aspects as mentioned by respondents. Even if graduates perceived themselves as good in communicating in English but as findings from DBU graduates employers showed that graduates have a remarkable deficiency in communicating in English. The finding is similar with the findings of ETQAA that showed the English language communication skills of graduates of HEIs of Ethiopia to be the most important [11].

\section{Conclusion}

Debre Berhan University's Bachelor degrees for graduates were evaluated as useful for job placement and a key for performing their job properly as much as the employers expected from graduates. The study programs offered to graduate were also found to be relevant because the programs are given based on the needs of the country. The University's graduates were reported to perform above average in most basic knowledge, skills and personal attributes, as evaluated by the graduates themselves and employers of graduates.

Regarding the levels of satisfaction of graduates and their employers in graduates overall performances, above average of the results were found "generally satisfied" or "very satisfied' as rated by most respondents. This is also cleared by the high ranking of the graduates that employers gave to DBU among other public universities in terms of producing qualified graduates. The aforementioned achievements do not absolve the University from its duty to make improvement. There are some deficient areas such as basic computer, research and English language skills of the graduates, lack or little chance of students' participation in staff research, some teachers' lack of experience, lack of sufficient counseling services, some students being unethical were also some of the pin pointed weaknesses consistently highlighted by the respondents.

\section{Recommendations}

Based on the findings of this study, the following recommendations are made.

1. Most of DBU graduates were found to be poor in basic computer and related technology skills in exception of some graduates from the CCS and CMHS. The University needs to encourage its students to be familiar with basic computer and related technology skills, by providing them with basic facilities and creating conducive environments in which students are motivated to use ICT regularly throughout their learning years.

2. English language communication skills were identified as a critical problem of DBU graduates. Therefore English language and the English Language Improvement Center (ELIC) of the University should take the initiative in offering continuous remedial classes of "Basic English language skills training programs" to as many students as possible.

3. Basic research skills was also identified as a great problem with DBU graduates therefore, the University needs to work on how to integrate adequate and competency-based research methodology courses in the curriculum or how to teach the research courses to the students to make them skillful with research methodology before graduated from the University. Work on involving students in staff research project to ensure students of the valuable hands on learning opportunities. To solve the problems the students must be participated in staff research could help students to internalize the skills of research.

4. High proportion of young and inexperienced staff at Debre Berhan University was identified as an obstacle to the quality of teaching and learning, and reducing the process to teacher-centered approach of teaching, corrective measures must be taken. These may include offering capacity building to inexperienced staff and recruiting more experienced ones.

5. The University's guidance and counseling services are proved to enhance performances as well as assisting students to develop personal qualities and social skills by giving different trainings.

6. The University must create proper opportunities for sharing of good practices among colleges, each college have success theories and challenges will be conductive to expanding and strengthening promising practices and innovative ideas throughout the University programs.

\section{Limitations}

The study only tries to see tracer study only on education quality hence; other variables which could be included under tracer study were not seen.

\section{Acknowledgements}

The authors are very grateful to Debre Berhan University for financial support. And also a great thanks for $\mathrm{Mr}$. Gezahegn Nega and Mr. Genanew Timerga during data collection and analysis.

\section{Authors' Contributions}

GT raised the research questions and developed the design of the study, performed the data entry and analysis, and participated in the manuscript write up. GT and GN involved in the preparation of designing the study involved during the 
analysis, interpretation and developed the manuscript and wrote the sections meticulously.

\section{Disclosure}

The authors declare that there is no conflict of interest in this work.

\section{References}

[1] St Mary University College (2008). Graduate Tracer study: Focus on Graduates from the Regular Division. Addis Ababa: Unity University College Printing Press.

[2] Higher Education Relevance and Quality Agency (HERQA) (2006 A) HERQA Institutional Quality Audit: HERQA profile. Addis Ababa: Ethiopia.

[3] Higher Education Relevance and Quality Agency (2006 B) HERQA Institutional Quality Audit: HERQA Institutional Audit Procedure. Addis Ababa: Ethiopia.

[4] Higher Education Relevance and Quality Agency (2006 C) HERQA Institutional Quality Audit: Areas of focus for Institutional Quality Audit. Addis Ababa: Ethiopia.

[5] Yamane, Taro. (1967) Statistics, an Introductory Analysis, 2nd ${ }^{\text {Ed }}$., New York: Harper and Row. Zembere, N.
Chinyama, M. (1996). The University of Malawi Graduate Tracer Study Retrieved on 07 August 2008 from the Association of African Universities Website: http://WWW.aau.org/studyprogram/notpub.

[6] Schomburg H. (2003) Handbook for Graduate Tracer Studies. University of Kassel:Germany. Retrieved from Http://WWW.qtafi.de/handbook V2.pdf on 18 April 2011.

[7] Mammo, W. (2007). Demise, renaissance orexistence of LIS education in Ethiopia curriculum, employers' expectations and professionals dreams. The International Information and Library Review, 39 (1), 145-57.

[8] Higher Education Relevance and Quality Agency (2008). Jimma University Institutional Quality Audit report. Addis Ababa: Ethiopia.

[9] Ncube, M. (2003) Where has all the Education Gone in Zimbabwe? Employment Outcomes Among Secondary School and University Leavers, Botswana Vocational training authority (2005).

[10] Olaniyan, A., and Okemakinde, T. (2008). Human Capital theory: Implications for Educational Development. European Journal of Scientific Research, 24 (2), 175-162.

[11] Education and Training Quality Assurance Agency \{ETQAA\} (2010). Employers, satisfaction recent graduates of Higher Education Institutions in Ethiopia: Unpublished report of survey conducted in 2009. 